\title{
Evaluation of potential health risk of arsenic-affected groundwater using indicator kriging and dose response model
}

\author{
Jin-Jing Lee ${ }^{\mathrm{a}}$, Cheng-Shin Jang ${ }^{\mathrm{b}}$, Sheng-Wei Wang ${ }^{\mathrm{a}}$, Chen-Wuing Liu ${ }^{\mathrm{a}, *}$ \\ ${ }^{a}$ Department of Bioenvironmental Systems Engineering, National Taiwan University, Taipei, 106, Taiwan ROC \\ ${ }^{\mathrm{b}}$ Department of Leisure and Recreation Management, Kainan University, Luzhu, Taoyuan, 338, Taiwan ROC
}

Received 13 January 2007; received in revised form 30 May 2007; accepted 8 June 2007

Available online 12 July 2007

\begin{abstract}
This study analyzed the potential health risk associated with the ingestion of arsenic-affected groundwater in the arseniasisendemic Lanyang plain of northeastern Taiwan. Indicator kriging was used to estimate arsenic concentrations in groundwater. Target cancer risk (TR) and dose response functions were adopted to evaluate the potential health risk based on the estimated arsenic concentration distributions. The estimated arsenic concentrations in groundwater reveal that arsenic concentrations $(>50 \mu \mathrm{g} / \mathrm{L})$ in well water are high in six townships — JiaoSi, YiLan, JhungWei, WuJie, DonShan and LouDon. Highest arsenic concentrations $(70.32 \mu \mathrm{g} / \mathrm{L})$ are in the YiLan and the JhungWei townships. The estimated TR values at the arsenic-affected townships are ten times more than an acceptable standard $\left(10^{-6}\right)$. The largest TR values are 145.5 and 91.2 times higher than an acceptable standard for males and females, respectively. The estimated annual mortalities by arsenic-induced internal cancers occur in the YiLan township (ten cases), LouDon (five cases), WuJie (three cases), JhungWei (two cases) and DonShan (one case). The highest number of mortalities per year in the study area is 24 . Residents of the six townships with high arsenic-affected groundwater should use tap water as drinking water and use groundwater only for other purpose. The well water in other townships in the Lanyang plain has no adverse effects on human health.
\end{abstract}

(C) 2007 Elsevier B.V. All rights reserved.

Keywords: Arsenic; Indicator kriging (IK); Dose response; Target cancer risk (TR)

\section{Introduction}

Arsenic is widely distributed in the Earth's crust and concentrated in pyrite, hydrous Fe oxides and sulfide compounds. Arsenic may dissolve in water from these minerals, depending on $\mathrm{pH}$, redox conditions and temperature (Smedley and Kinniburgh, 2002) and thus be transported in the environment in the water. The main source of arsenic exposure for the general population is the

\footnotetext{
* Corresponding author. Tel.: +88622362 6480; fax: +88622363 9557.

E-mail address: 1cw@gwater.agec.ntu.edu.tw (C.-W. Liu).
}

ingestion of drinking water with high levels of arsenic (WHO, 1981; ATSDR, 1993). In a rural area on the southwestern coast of Taiwan, blackfoot disease (BFD) is known as an endemic peripheral vascular disease. Arsenic has been identified as a major risk factor for BFD (Shen and Chin, 1964; Tseng, 1977). Ingestion of arsenic compounds in well water has also been associated with age-adjusted mortality from diabetes (Lai et al., 1994), hypertension and cerebrovascular disease (Brown and Chen, 1995), and cancers of the lung, liver, bladder and kidney, prostate and nasal cavity (Wu et al., 1989; Chen and Wang, 1990).

Chiou et al. (1997) investigated that the arsenic contents of groundwater in the Lanyang plain that 
exceeded the current Taiwan EPA limit of $10 \mu \mathrm{g} / \mathrm{L}$ for drinking water, and those of some wells are up to $600 \mu \mathrm{g} / \mathrm{L}$ or higher. Chen et al. (1995) indicated that arsenite and arsenate represented $87 \%$ and $5.8 \%$, respectively, of the total arsenic content in the well water in the Lanyang plain. Since groundwater is abundant, the residents of the Lanyang plain have used shallow wells (depths $<40 \mathrm{~m}$ ) to obtain drinking water since 1940s (Chiou et al., 2000). A tap water system has been established in the early $1990 \mathrm{~s}$, and over $90 \%$ of households have tap water served. However, groundwater is still commonly used as a source of drinking water (Chiou et al., 2000). The residents have used higharsenic artesian well water over 50 years (Chiou et al., 1997). Significant dose-dependent relationships were established between the arsenic concentration in well water and an increased risks of cerebrovascular disease, urinary cancer and other cancers (Chiou et al., 1997, 2000, 2001), moreover, adverse pregnancy outcomes (Yang et al., 2003) was found and warrants further attention.

The estimation of spatial distribution of contaminant groundwater quality is very important in the health risk assessment. The accuracy of the direct analysis of in-situ data is often dubious because the field investigation is limited by time and cost and the observations contain considerable uncertainty. Geostatistics, therefore, is widely used for the spatial estimation with the consideration of spatial variability. Specifically, indicator kriging (IK) (Goovaerts, 1997) and Bayesian Maximum Entropy method (BME) (Christakos, 2000) are both more advanced due to their ability to take the data uncertainty into account. IK has been widely applied on the analysis of the soil contamination (Smith et al., 1993; Oyedele et al., 1996; Juang and Lee, 1998; Castrignanò et al., 2000; van Meirvenne and Goovaerts, 2001; Lin et al., 2002), and the estimation of its relation to spatial distribution of health risk (Istok and Pautman, 1996; Saisana et al., 2004; Liu et al., 2004; Juang et al., 2004; Jang et al., 2006). BME has also been applied on spatial health risk assessment on many topics, such as the arsenic study (Serre et al., 2003; Lee et al., 2005), and influenza mapping in California (Choi et al., 2003). Among them, IK is a frequently adopted as a nonparametric geostatistical method. IK makes no assumption regarding the distributions of variables, and a $0-1$ indicator transformation of data is adopted to ensure that the predictor is robust to outliers (Cressie, 1985). In an unsampled location, the values estimated by IK represent the probability that does not exceed a particular threshold. Therefore, the expected value derived from indicator data is equivalent to the cumulative distribution function of the variable (Smith et al., 1993). The incorporation of epidemiological framework with IK has been discussed in the studies of the estimation of lung cancer risk (Vieira et al., 2002), and the impact on human health and potential remedies for arsenic-containing drinking groundwater in Bangladesh (Yu et al., 2003).

To evaluate the risk of long-period exposure to arsenic, this study adopted indicator kriging to estimate arsenic exposure distributions in well water in the Lanyang plain of northeastern Taiwan. The target cancer risk and cancer dose response function of ingested arsenic in well water were mapped to evaluate the potential risk to human health and population mortality, respectively. The results of the probabilistic risk assessment provide suitable utility modes of groundwater in the arseniasis-endemic Lanyang plain.

\section{Study area}

The Lanyang plain, located in YiLan County in northeastern Taiwan, is the alluvial fan of the Lanyang river. The area is triangular, with the Pacific Ocean next to the east, the Snow mountains to the northwest and the Central mountains to the southwest. The main river, the Lanyang river, flows through the middle of the area from west to east (Fig. 1). The area is approximately $400 \mathrm{~km}^{2}$, with sides of about $30 \mathrm{~km}$ each. The study area consists of ten townships, which contain $97 \%$ of the populations (about 451,000) of the YiLan County. The groundwater flows from west to east. The western parts of the plain near by the Snow and Central mountains form the main recharging area of groundwater, and rain water is the main source of groundwater.

Although a high percentage of households have been served by tap water, groundwater is still used as a popular source of drinking water of residents in the study area. The arsenic levels in the well water in different regions are markedly varied. The main source of exposure to inorganic arsenic among residents is the ingestion of groundwater from wells (Chiou et al., 2001). Arsenic in groundwater mainly results by geogenic release from sedimentary formation of the marine deposit formed in Quaternary period (Chen et al., 1995; Chiou et al., 2001; Shen, 2006).

\section{Materials and methods}

\subsection{Well water samples}

This study used data surveyed by the Environmental Protection Bureau (EPB) of the YiLan County Government 


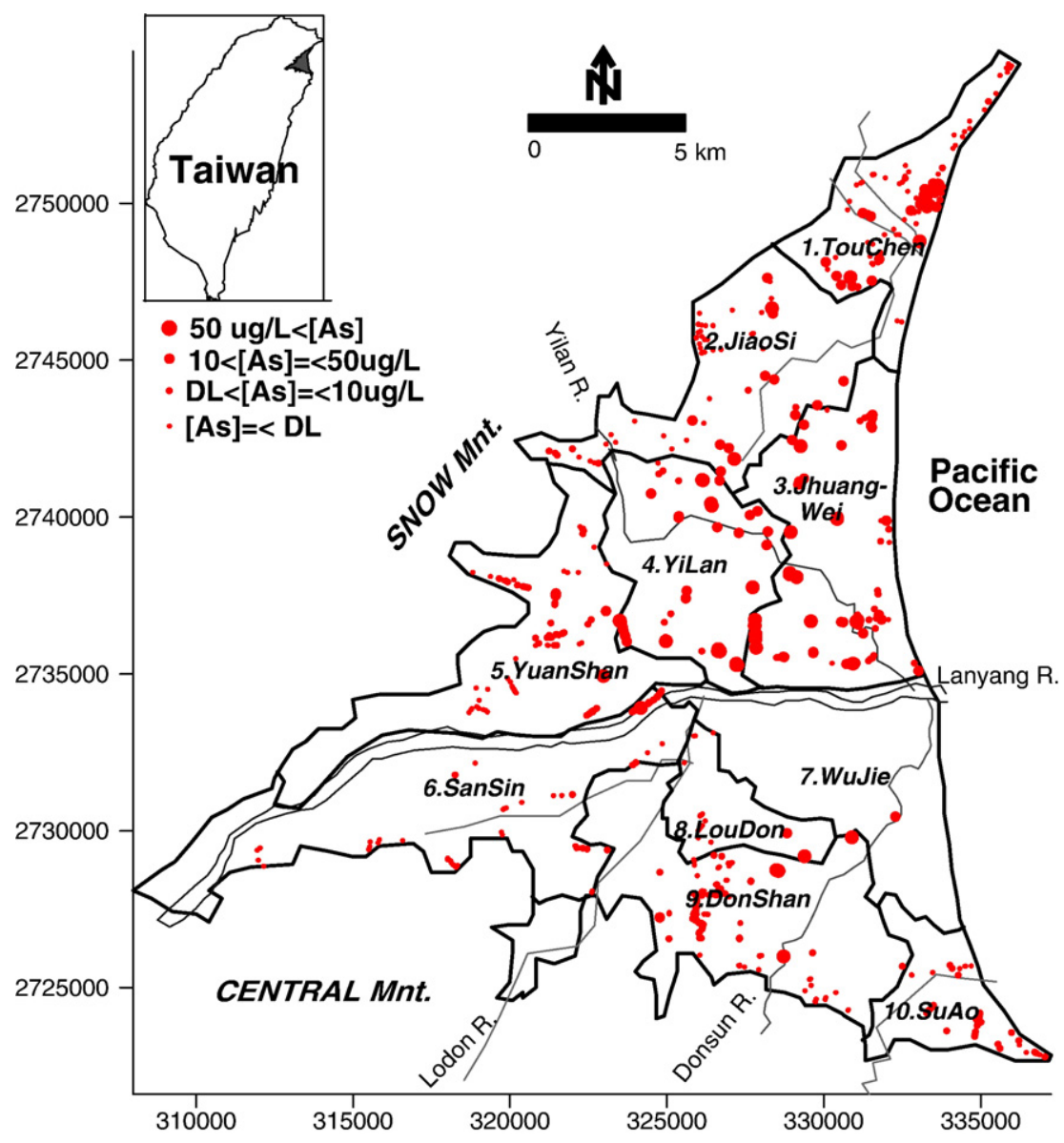

Fig. 1. Study area and spatial distribution of measured arsenic concentration.

(EPB, 1997, 1998, 1999) during 1997-1999. A total of 929 well water samples were collected in the study area. The spatial distributions of 929 arsenic concentration data were shown in Fig. 1. All of groundwater samples were collected from household wells. The well water was run through the pumping tube for at $10 \mathrm{~min}$ before sampling. Seven water quality items were analyzed, including concentrations of arsenic, $\mathrm{pH}$, ammonia $\left(\mathrm{NH}_{3}\right)$, nitrite $\left(\mathrm{NO}_{2}^{-}-\mathrm{N}\right)$, nitrate $\left(\mathrm{NO}_{3}^{-}-\mathrm{N}\right)$, iron $(\mathrm{Fe})$ and manganese $(\mathrm{Mn}) \cdot \mathrm{pH}$ was measured in-situ in the field. Other items were analyzed in the laboratory. The analysis procedures of arsenic concentration followed the APHA Method 3500-AsB. Water samples were filtered with $0.45 \mu \mathrm{m}$ glass microfiber filter papers and acidified with $\mathrm{HNO}_{3}$ (Merck ultra pure grade) to $\mathrm{pH}<2$. A graphite furnace atomic absorption spectrometer (GFAAS, Perkin Elmer Model 2100), a hydride generation system (HG, MHS-10) and an automatic sampler (AS-70) were adopted in As analysis, with the detection limit of $0.9 \mu \mathrm{g} / \mathrm{L}$. An FAAS was used to analyze the determination of $\mathrm{Fe}$ and $\mathrm{Mn}$; Nesslerization method, Colorimetric method and Ultraviolet Spectropho- tometric Screening method were used for $\mathrm{NH}_{3}, \mathrm{NO}_{2}^{-}-\mathrm{N}$ and $\mathrm{NO}_{3}^{-}-\mathrm{N}$, respectively. Strict quality control procedures, such as reagent blank analysis, field blank analysis, duplicated test and check test, have been executed during the field sampling (EPB, 1997, 1998, 1999). The average arsenic concentration was $11.8 \mu \mathrm{g} / \mathrm{L}$, with the maximum of $772 \mu \mathrm{g} / \mathrm{L}$. Approximately $49.5 \%$ of the 929 samples were below the instrumental detection limit $(<0.9 \mu \mathrm{g} / \mathrm{L})$. This study used a half of the instrumental detection limit to represent the value below the instrumental detection limit (Preez et al., 2003; Gaus et al., 2003).

\subsection{Geostatistic approach}

\subsubsection{Variogram analysis}

Geostatistical approaches are based on the regionalized variable theory, which states that variables in an area exhibit both random and spatially structured properties (Journel and Huijbregts, 1978). The geostatistical spatial assumption is typically that the regionalized variable is second-order stationary. A geostatistical 
variogram of the data must initially be determined. The variogram quantifies the spatial variability of the random variables between two sites. The experimental variogram is fitted using a theoretical model, $\gamma(h)$, which may be spherical, exponential or Gaussian, to determine three parameters, including the nugget effect $\left(c_{o}\right)$, the sill $(c)$ and the range $(a)$. The variogram can be computed in different directions to detect any spatial anisotropy of the spatial variability. This study adopted a geometric anisotropic model which yields variograms with the same structural shape and variability (sill+ nugget) but a direction-dependent range for the spatial correlation (Deutsch and Journel, 1998).

\subsubsection{Indicator kriging}

Indicator kriging is a non-parametric geostatistical method for estimating the probability that the attribute value is no greater than a specific threshold, $z_{k}$, at a given location $\boldsymbol{u}$ (Goovaerts, 1997). In IK, the spatial variable, $Z(\boldsymbol{u})$, is transformed into an indicator variable with a binary distribution, as follows.

$I\left(\mathbf{u} ; z_{k}\right)=\left\{\begin{array}{lc}1, & \text { if } Z(\mathbf{u}) \leq \mathrm{z}_{k} \quad, k=1,2, \ldots . . m \\ 0, & \text { otherwise }\end{array}\right.$.

The expected value of $I\left(\boldsymbol{u} ; z_{k}\right)$, conditional on $n$ surrounding data, can be expressed as,

$E\left[I\left(\mathbf{u} ; z_{k} \mid(n)\right)\right]=\operatorname{Prob}\left\{Z(\mathbf{u}) \leq z_{k} \mid(n)\right\}=F\left(\mathbf{u} ; z_{k} \mid(n)\right)$

where $F\left(\boldsymbol{u} ; z_{k} \mid(n)\right)$ is the conditional cumulative distribution function (ccdf) of $Z(\boldsymbol{u}) \leq z_{k}$. Indicator kriging is an estimation technique which is based on an estimator that is defined as,

$I^{*}\left(\mathbf{u}_{0} ; z_{k}\right)=\sum_{j=1}^{n} \lambda_{j}\left(z_{k}\right) I\left(\mathbf{u}_{j} ; z_{k}\right)$

where $I\left(\boldsymbol{u}_{j} ; z_{k}\right)$ represents the values of the indicator at the measured locations, $\boldsymbol{u}_{j}, j=1,2, \ldots, n$, and $\lambda_{j}$ is a weighting factor of $I\left(\boldsymbol{u}_{\boldsymbol{j}} ; z_{k}\right)$ used in estimating $I^{*}\left(\boldsymbol{u}_{0} ; z_{k}\right)$.

\subsection{Assessment of risk to human health}

The Risk Assessment Forum reassessed the risk of cancer that is associated with the ingestion of inorganic arsenic. The US EPA Region III Risk-Based Concentration Table (US EPA, 1988, 1996) supports a method for estimating the target cancer risk (TR). The carcinogenic risk associated with inorganic arsenic is expressed as an excess of the probability of contracting the cancer over a lifetime of 70 years. A model for estimating target cancer risk (lifetime cancer risk) is

$\mathrm{TR}=\frac{\mathrm{ED} \cdot \mathrm{IR} \cdot C_{\mathrm{w}} \cdot \mathrm{EF} \cdot \mathrm{CPS}}{\mathrm{BW} \cdot \mathrm{AT}} \cdot 10^{-3}$

where TR is the target cancer risk (the incremental individual lifetime cancer risk); $\mathrm{EF}$ is the exposure frequency ( 365 days/years); IR is the ingestion rate $(2 \mathrm{~L} /$ day) (EPA of Taiwan, 1998); $C_{\mathrm{w}}$ is the arsenic concentration of arsenic in the well water $(\mu \mathrm{g} / \mathrm{L})$; ED is the duration of exposure (70 years), and CPS is the carcinogenic potency slope $\left[0.0662\right.$ and $0.0365(\mathrm{mg} / \mathrm{kg} \text { day })^{-1}$ for males and females, respectively] (Chen et al., 1962). BW is the body weight of a Taiwanese adult (64 kg and $56.3 \mathrm{~kg}$ for males and females, respectively) (http://www.doh.gov.tw/ statistic/data); AT is the averaging time for carcinogens (25,550 days). An estimated TR value of over one million is typically considered to represent a hazard to human health.

Arsenic-induced cancers may cause death when the TR values are high. The ingestion of arsenic dose may be related to cancer mortality. The National Research Council $(1999,2001)$ used data from the Taiwanese studies by Chen et al. (1985) and Wu et al. (1989) to estimate a dose response function of arsenic concentration of each gender and age. A dose response model was established that based on estimated or observed cancer frequencies by age and arsenic concentration, and a maximum-likelihood model with point estimates of distributions of concentration and age in the data intervals,

$h(c, t)=k\left(q_{1} c+q_{2} c^{2}\right) \cdot(t-m)^{k-1} H(t-m)$

where $h(c, t)$ denotes an incidence rate, $c$ denotes arsenic concentration (ig/L); $t$ denotes age; $H$ is the Heaviside function, $H(t-m)=0$ for $t<m$ and $H(t-m)=1$ for $t \geq m$, and the parameters $q_{1}, q_{2}, k$ and $m$ are nonnegative. Table 1 shows the values of parameters $q_{1}, q_{2}, k$ and $m$ in Eq. (5) for lung, bladder and liver cancers for each gender. The function shows that the different type cancer of interest at age $m$ for someone exposed at arsenic concentration $c$, and $q_{1}, q_{2}$ and $k$, are the best-fitting regression parameters of dose response function of the specific cancer.

Yu et al. (2003) derived a dose response function of arsenic concentration (but not by age) for each gender by averaging the dose response function given by Eq. (5) over the distribution of ages in Bangladesh. They modeled an age distribution as an exponential distribution with parameter $\lambda$, obtaining a weighted average and age-adjusted dose response function is,

$h(c)=\int_{0}^{\infty} h(c, t) \lambda \cdot \exp (-\lambda t) \mathrm{d} t$. 
Table 1

Values of parameters that govern arsenic-induced cancers

\begin{tabular}{|c|c|c|c|c|}
\hline Gender & $q_{1}$ & $q_{2}$ & $k$ & $m$ \\
\hline \multicolumn{5}{|c|}{ Lung cancer } \\
\hline Male & $1.4672 \times 10^{-11}$ & 0 & 3.9195 & 21.4946 \\
\hline Female & 0 & $6.1194 \times 10^{-14}$ & 3.5137 & 17.0978 \\
\hline \multicolumn{5}{|c|}{ Bladder cancer } \\
\hline Male & 0 & $7.3394 \times 10^{-17}$ & 5.1306 & 14.7025 \\
\hline Female & 0 & $2.2225 \times 10^{-13}$ & 3.4732 & 33.0365 \\
\hline \multicolumn{5}{|c|}{ Liver cancer } \\
\hline Male & $3.6947 \times 10^{-14}$ & $4.9984 \times 10^{-13}$ & 2.9054 & 16.8998 \\
\hline Female & $2.8015 \times 10^{-11}$ & $4.9395 \times 10^{-13}$ & 2.7282 & 25.9420 \\
\hline
\end{tabular}

Estimated by NRC (1999, 2001).

The age-adjusted dose response model of Eq. (6) was adopted in the study. The average ages of males and females in Taiwan are $35.65 \mathrm{yr}$ and $36.09 \mathrm{yr}$, according to a 2004 survey of the Ministry of the Interior (MOI) of Taiwan (ROC). Therefore, the derived $\lambda$ values of males and females used in Eq. (7) are 0.02805 and 0.02771, respectively.

\section{Results and discussion}

\subsection{Spatial distribution of arsenic concentrations}

The measured arsenic concentrations, $<0.9 \mu \mathrm{g} / \mathrm{L}$, $1.4 \mu \mathrm{g} / \mathrm{L}, 3 \mu \mathrm{g} / \mathrm{L}, 7.34 \mu \mathrm{g} / \mathrm{L}$ and $22 \mu \mathrm{g} / \mathrm{L}$, at the 49.5 th, 60th, 70th, 80th, 90th percentiles on the percentage frequency distribution of arsenic concentrations (Fig. 2), respectively, were taken as the five threshold values (Goovaerts, 1997), which were employed to derive the conditional cumulative distribution function (ccdf) at each estimated grid point. An omnidirectional variogram was first used to analyze the spatial structures of arsenic concentration. A lag increment of $1 \mathrm{~km}$ was adopted to obtain a stable variogram structure (Fig. 3). An exponential model yields the best fitting in the variograms (Fig. 3) and its function is expressed as (Deutsch and Journel, 1998),

$\gamma(h)=c_{0}+c\left[1-\exp \left(-\frac{3 h}{a}\right)\right]$.

Table 2 reveals that the fitting ranges, nugget effects and sills are 9-18 km, 0.01-0.1 and 011-0.23, respectively. Because a geometric anisotropic model had similar structural shape and variability (sill + nugget) as the omnidirectional variogram model, the omnidirectional variograms was adopted to analyze the geometric anisotropic variability. The anisotropic ratios (maximum range/minimum range) range from 1.5 to 2.63 (Table 2).

Indicator kriging was employed to estimate the probability distribution of arsenic concentrations based on variogram models. The study area was horizontally discretized by a grid of 1361 cells, with a spacing of $0.5 \mathrm{~km}$. Additionally, the standard limiting arsenic concentration of Taiwanese drinking water, $10 \mu \mathrm{g} / \mathrm{L}$, corresponded to the $82.5 \%$ of the frequency distribution of the measured arsenic concentrations. Therefore, the 0.825-quantile estimate was used to determine an As-

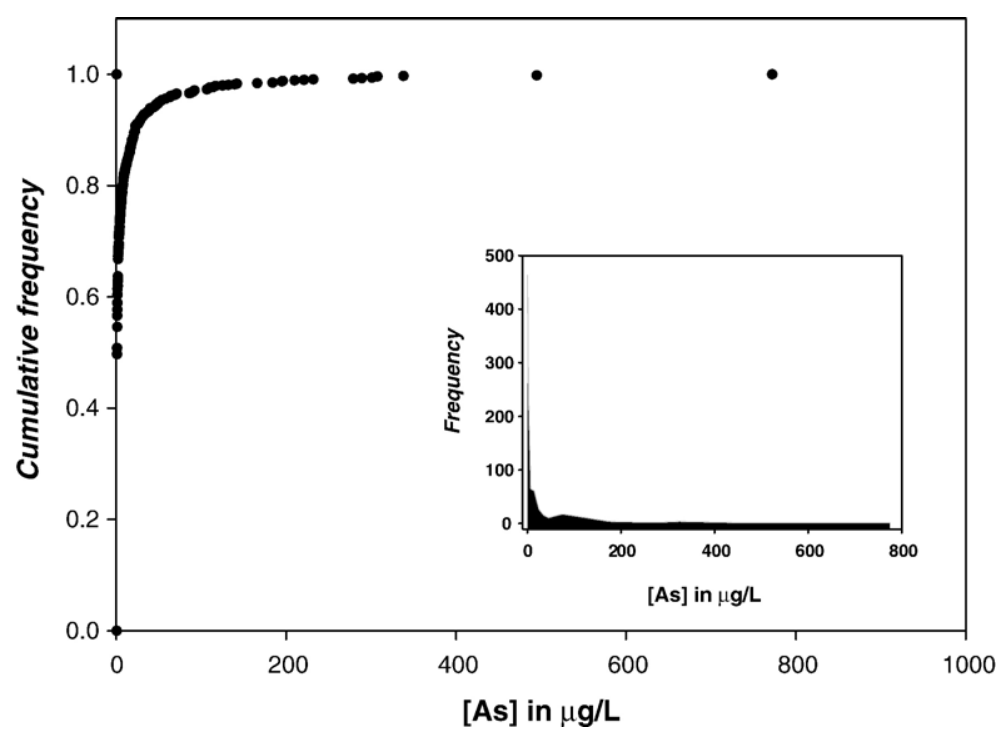

Fig. 2. Cumulative frequency of measured arsenic concentrations. 

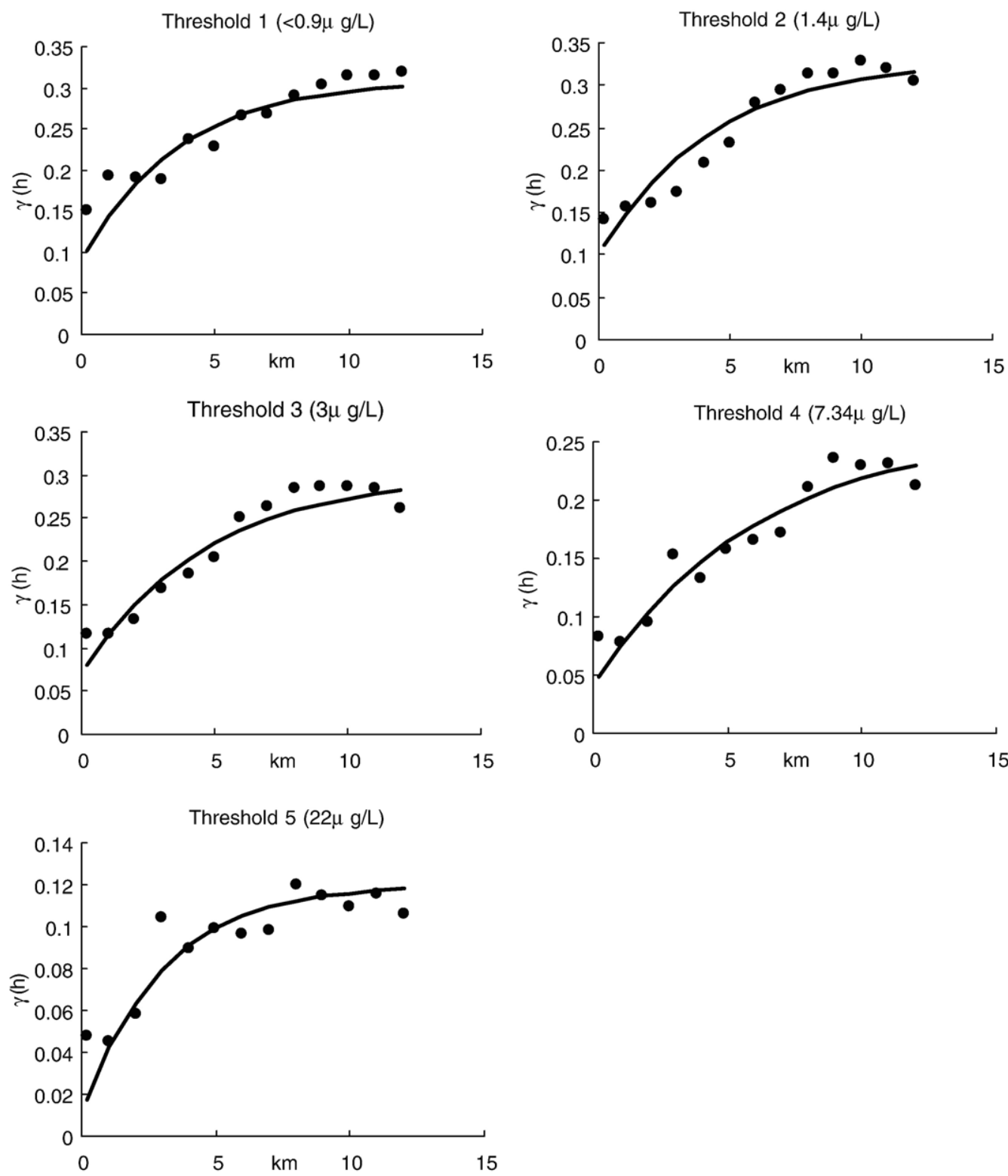

Fig. 3. Experimental variogram indicator of arsenic concentrations and the fitting of theoretical models in horizontal directions for five threshold values.

contaminated concentration based on a ccdf at each cell (Goovaerts, 1997). That is, the cumulative probability of 0.825 in a ccdf at each cell responds to the As-polluted concentration. Fig. 4a plots the estimated arsenic concentration at each cell. Arsenic concentrations $(>50 \mu \mathrm{g} / \mathrm{L})$ in well water were high in six townships, including JiaoSi, YiLan, JhungWei, WuJie, DonShan and LouDon. The cells with the highest estimated arsenic concentrations $(70.32 \mu \mathrm{g} / \mathrm{L})$ were in the YiLan and the JhungWei townships.
4.2. Potential health risk associated with ingested arsenic in well water

Fig. $4 \mathrm{~b}$ and $\mathrm{c}$ show the spatial maps of estimated TRs for each gender by Eq. (4). The largest TR values were 145.5 and 91.2 times higher than the acceptable standard (one millionth, $10^{-6}$ ) for males and females, respectively. The TR values in the arsenic-affected townships of DonShan, JiaoSi, JhungWei, LouDon, TouChen, WuJie and YiLan (Fig. 5) were one order of magnitude 
Table 2

Fitted parameters of the exponential model for five threshold values of arsenic indicator variable

\begin{tabular}{lllllc}
\hline Threshold & $\begin{array}{l}\text { Nugget } \\
\text { effect }\left(c_{o}\right)\end{array}$ & $\begin{array}{l}\text { Sill } \\
(c)\end{array}$ & $\begin{array}{l}\text { Range }(a) \\
(\mathrm{km})\end{array}$ & $\begin{array}{l}\text { Max. range } \\
(\mathrm{km})\end{array}$ & $\begin{array}{l}\text { Min. range } \\
(\mathrm{km})\end{array}$ \\
\hline 1st & 0.09 & 0.22 & 11 & 15 & 8 \\
2nd & 0.1 & 0.23 & 13 & 15 & 8 \\
3rd & 0.07 & 0.23 & 14 & 16 & 9 \\
4th & 0.04 & 0.22 & 18 & 21 & 10 \\
5th & 0.01 & 0.11 & 9 & 12 & 7 \\
\hline
\end{tabular}

higher than the acceptable standard. The TRs in other townships of SuAo, ShanShin and YuanShan are generally lower than the acceptable standard, but a few high TR values do present. The results reveal that high arsenic TR levels are sparsely distributed. Residents have a considerable high risk of cancer in the six high arsenic concentration townships regions when drinking groundwater for a long period.

People exposed to arsenic were based on an estimated arsenic concentration of groundwater in each cell. The measurement units and health effects were fatalities per year due to lung, bladder, and liver cancers. In a township evaluation (Yu et al., 2003), $c$ was a cell arsenic concentration and $n_{c}$ denoted the estimated number of people who were exposed to the corresponding arsenic concentration. (that is, a population density (persons $/ \mathrm{km}^{2}$ ) in each township) (data available on http://bgacst.e-land.gov.tw/bgacst2/)). This distribution combined with a dose response function $h$ (c) (annual mortality rate) were used to estimate annual mortalities for the townships and the study area. Fig. 6 shows that the annual mortality rates $(h(c))$ in ten townships of males and females. The variations of annual mortality rate $(h(c))$ are large in eight townships except ShanShin and SuAo, indicating that the distributions of estimated arsenic concentrations vary greatly within each township. Internal cancers of males are greater than those of females. Among them, lung cancer and bladder cancer are the highest found in male and female, respectively.

Fig. 7 refers to the epidemiological studies in the study area, indicating the incidence rate of internal cancers associated with arsenic in drinking water in the northeastern Taiwan. These studies focus on four townships in the Lanyang plain covered JiaoSi, JhungWei, WuJei and DonShan, for a total of 18 villages. All of these villages are located in regions of high arsenic concentrations in the Lanyang plain. The incidence rate of each cancer type in these studies is generally one or two order higher than estimated mortality rates of male and female in this study,
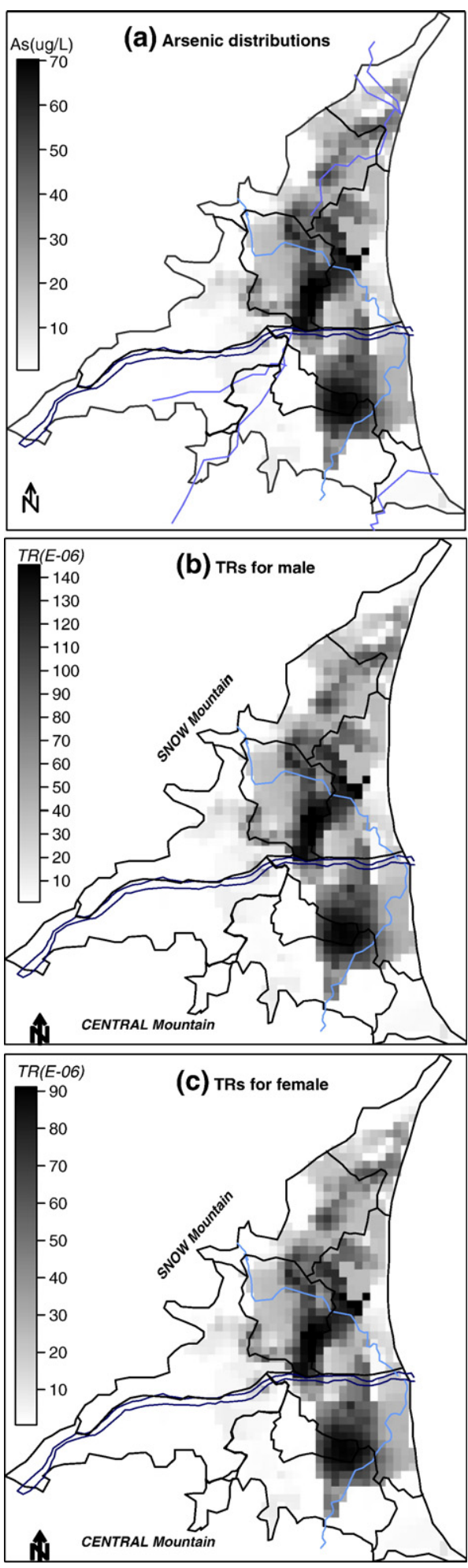

Fig. 4. Distributions of arsenic concentrations and estimated TRs for each gender in the Lanyang plain. 


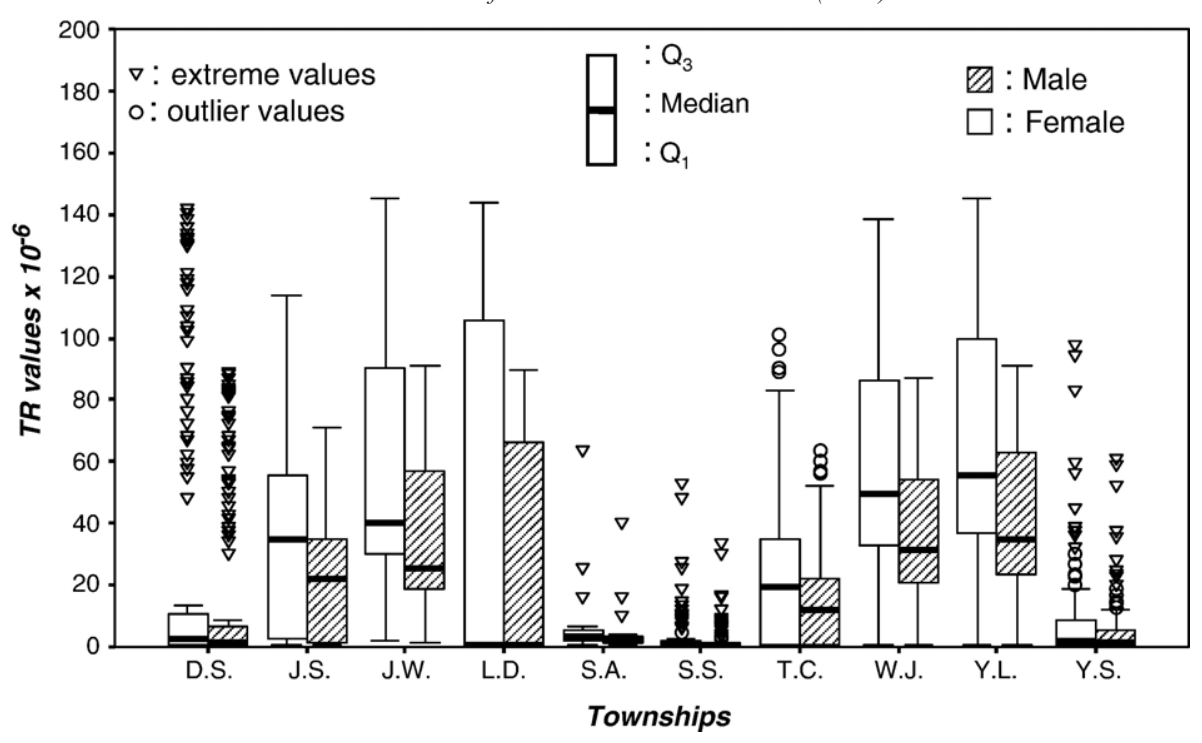

Fig. 5. TR values from long-term ingestion of arsenic in each township for each gender.

respectively. The incidence rate only represents the new occurrence rate of internal cancer in a period, whereas the mortality rate represents the rate of death caused by internal cancer. The former should be much higher than the latter. An incident case can be either recovery by medical care or death. Additionally, the death of the incident case may be attributed to other diseases or factors. Other possible reasons as follows. Firstly, ingesting arsenic is not the direct or main factor for internal cancers (David and Montalbano, 1985; Lee et al., 1988; Chiou et al., 1997). Secondly, the cited studies in which the participants who were more than 40 years old and have drunk groundwater with high arsenic concentrations for a long period. Accordingly, the number of cases may have been skewed upward. Moreover, these studies could not differentiate that occurrence of internal cancers were caused solely by ingesting arsenic-affected well water. Notably, a total of 39 persons died from internal cancers between 1991 and 1995 (Chen, 1997) - an average of only eight persons each year. Thirdly, the dose response function (Eq. (6)) subtracts a background dose response function from a total dose response function, the estimated mortality rate is solely due to arsenic-induced internal cancer (NRC, 1999, 2001).

The annual mortalities were estimated for each township. For male, the annual mortalities due to arsenic-induced lung, liver and bladder cancers were sixteen, zero and five cases, respectively. For female, the annual mortalities due to arsenic-induced lung, liver and bladder cancers were one, zero and two cases, respectively. Most annual mortalities due to arsenic-induced internal cancers occurred in the YiLan township (ten cases), LouDon (five cases), WuJei (three cases), JhungWei (two cases) and DonShan (one case). The estimated highest number of mortalities per year in the study area was 24 (equivalent to five mortalities per 100,000 persons). According to the $\mathrm{DOH}$, Taiwan (http://www.doh.gov.tw/statistic/data/), hundreds of people died from the three internal cancers each year from 1998 to 2005 . The estimated mortalities due to arsenic-induced internal cancer were much lower than the actual number of deaths due to internal cancers. Thus, other carcinogenic factors, such as lifestyle factors, were important (NRC, 1999, 2001). The ingestion of arsenicinduced liver cancer was relatively low in this study. Several studies (Fig. 7) show a markedly increased risk of developing cancers of the liver, lung, and bladder, but liver cancer incidence is not statistically significantly, or is at least only weakly correlated with ingestion of arsenic (Morales et al., 2000; Shen, 2006). Additionally, hepatitis types $\mathrm{B}$ and $\mathrm{C}$ which are prevalent in Taiwan, may transform into liver cancer at an age of over 40 years, confounding the diagnosis of arsenic-induced cancer (DOH, 2002). The lung cancer risk is more strongly correlated with smoking than with the ingestion of arsenic (Chen et al., 2004; Shen, 2006). The bladder cancer may be caused by arsenic in a biologic gradient of less than $50 \mu \mathrm{g} / \mathrm{L}$ (Chiou et al., 2001).

This study found that arsenic-affected groundwater is sparsely distributed at particular sites (small villages). The arsenic concentrations vary strikingly among wells in a given township resulting the exposure of arsenic through consumption of well water varied markedly. 
(a) Male

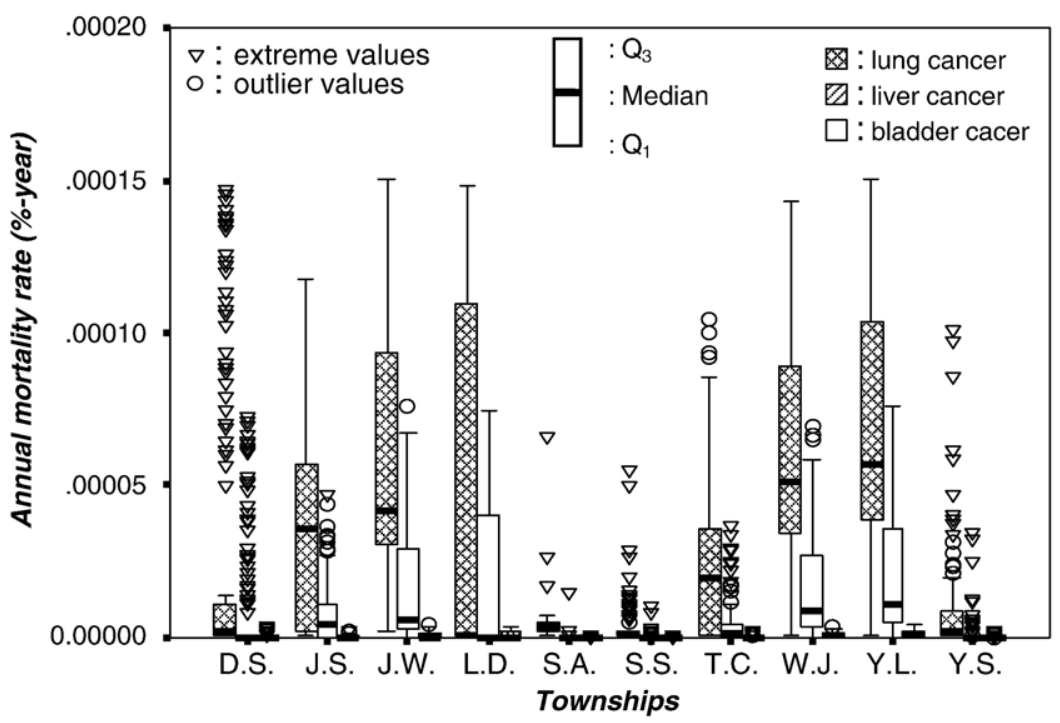

(b) Female

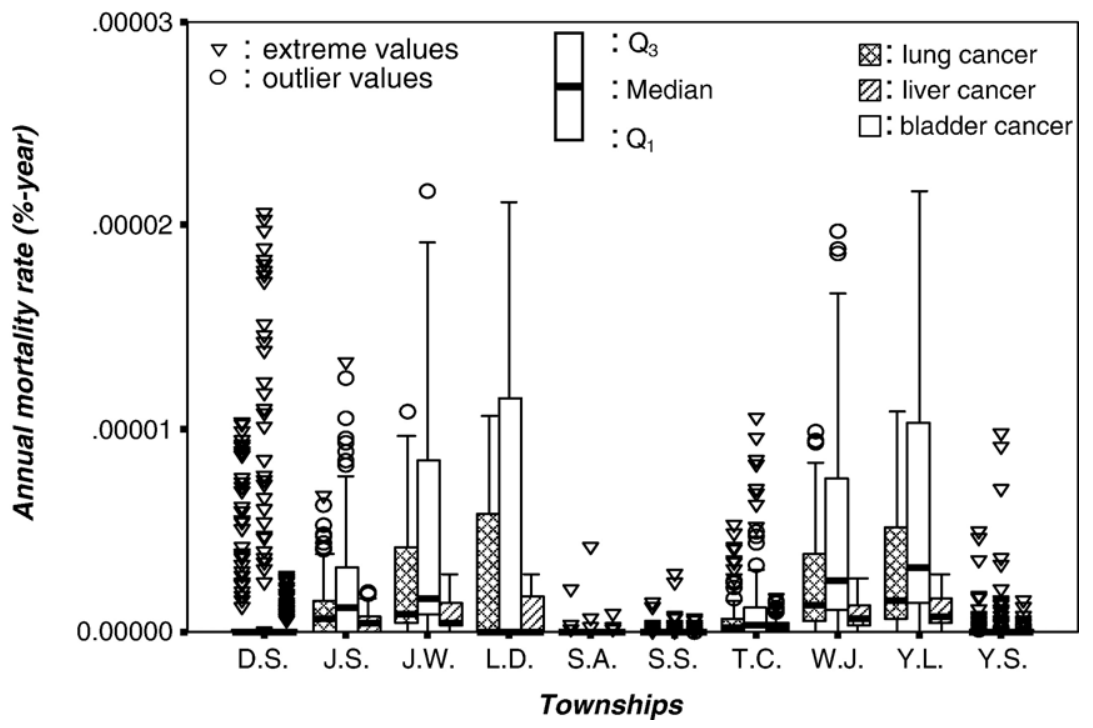

Fig. 6. Estimated annual mortality rate due to arsenic-induced internal cancers for each gender.

Variations among cancer mortality rates may exceed 1000 fold. Therefore, residents at the high arsenicaffected sites should not use groundwater as drinking water, and use groundwater only for household cleaning purpose.

\subsection{Uncertainty}

The dose response function is based on a set of data from the arseniasis-endemic area in southwestern Taiwan. Both residents that lived in the southwestern and the northeastern Taiwan have similar socioeconomic status, lifestyles and medical care facilities. In the southwestern Taiwan, residents used a few wells in each village, and median arsenic levels in well water were used to derive individual exposure to ingesting arsenic. In the northeastern Taiwan, each household obtained its drinking water from its own well. Uncertainties in health evaluations and target risk primarily are from (1) the distribution of arsenic concentration over the groundwater wells, and (2) the dose response function expresses as a function of arsenic concentration. 


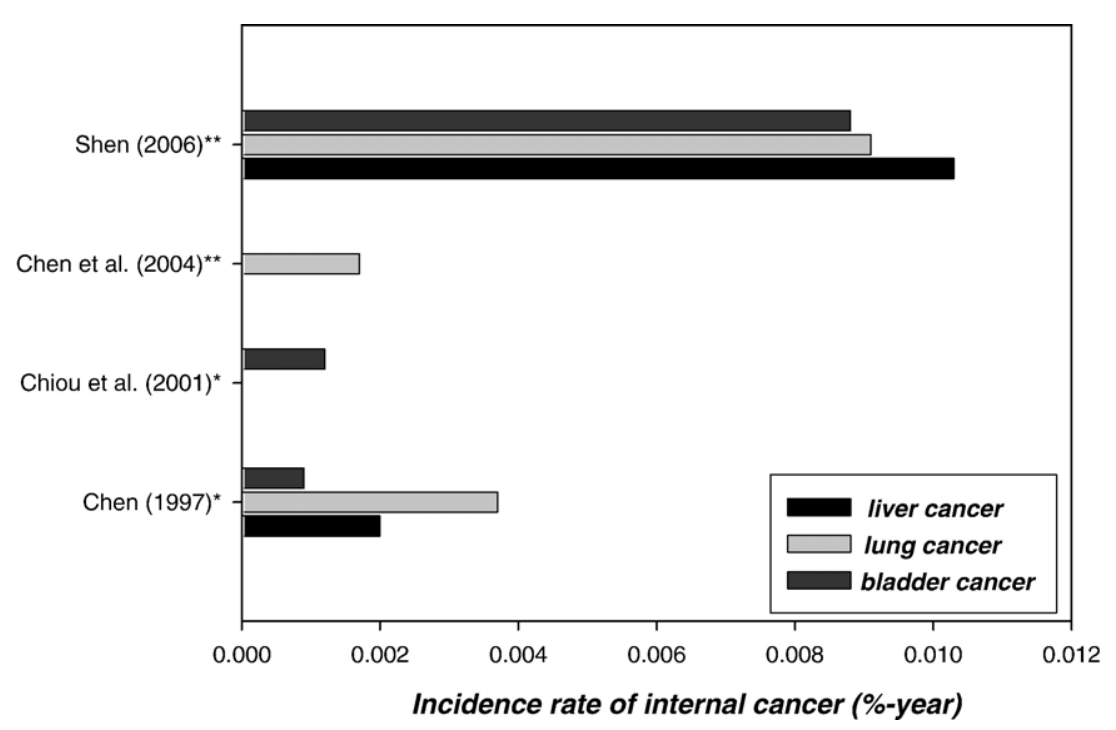

Fig. 7. Epidemiological studies of internal and skin cancers of residents who had drunk arsenic in drinking water in the northeastern Taiwan. $(* *$ : study areas include southwestern and northeastern (Lanyang plain) Taiwan. *: study area was in northeastern (Lanyang plain) Taiwan).

The spatiotemporal distribution of arsenic concentrations in well water of each township may be markedly varied. To recovery the spatial variability of arsenic concentrations this study adopted 929 household well water sampling from 1997 to 1999 . The distribution of these sampled wells was carefully selected to represent the background concentration of arsenic in the study area (EPB, 1997, 1998, 1999). Moreover, this study estimated the point distribution of arsenic concentration using a grid of 1361 cells with a spacing of $0.5 \mathrm{~km}$ to capture closely the fact that each household has its own well. Wells with high arsenic concentrations present only at certain sites, reducing an increase in bias associated with the large scale used. Another uncertainty is that the assumption of the distribution of arsenic concentration remains constant over time. According to the quarterly analysis of data on groundwater quality from the monitoring wells of the EPA (available at http://wq.epa.gov.tw/WQ/Public2/ImageGW.asp/), the arsenic-affected regions did not significantly changed with time. The uncertainty of the use of constant arsenic concentration in estimating the target cancer risk is relatively low.

Estimating dose response function does not provide individual risk assessments, but rather, the annual mortalities for a population. This study adopted IK to provide results that are as close as possible to accurately evaluate exposure assessments at a fine grid level. Evaluations of health effects which capture the variation with arsenic concentrations among grid cells may thus lower the uncertainty of the estimated target cancer risk. However, other uncertainties involved in the health risk assessment are unable to be resolved in this study. Firstly, evaluations of dose response functions (exposure to more than $1 \mu \mathrm{g} / \mathrm{kg} /$ day) and target risk function are based on lifetime exposure. Therefore, some residents may not be continuously exposed to arsenic through drinking groundwater after having tap water been served. Moreover, the immigrants from other country whom previously have not exposed to arsenicaffected water also affect estimated results.

Secondly, the risk assessment model based on the dose response function for high exposure levels could not be directly adopted to predict those at low exposure level (Snow et al., 2005). At low arsenic dose levels (less than $50 \mu \mathrm{g} / \mathrm{L}$ ), the dose response curve might be a sublinear curve for arsenic carcinogenicity (NRC, 1999, 2001; Snow et al., 2005; Lamm et al., 2006), and the estimated risk could be under- or over-estimated (Crump, 1984), or might be non-carcinogenic risk assessment (Crump, 1984; Lamm et al., 2006). Many of the measured arsenic concentrations in this study area are low (much less than $1 \mu \mathrm{g} / \mathrm{kg}$ ), and lifetime exposure to low arsenic concentrations may induce only low to trivial probability of cancer incidence. These health risks estimated in the districts with low arsenic concentrations limit the validity of the health risk assessment results in this study.

\section{Conclusions}

Arsenic concentrations in well water were measured throughout the Lanyang plain of northeastern Taiwan by 
the YiLan County Government. The arsenic concentration exceeded the Taiwanese drinking water limit $(10 \mu \mathrm{g} / \mathrm{L})$ in some townships, and may pose a potential threat to human health. This study estimated arsenic concentrations in groundwater in the Lanyang plain by indicator kriging. Furthermore, the target cancer risk and the dose response functions provide the number and severity of various cancers in the affected population, respectively. The estimated arsenic concentrations in groundwater are high $(>50 \mu \mathrm{g} / \mathrm{L})$ in six townships JiaoSi, YiLan, JhungWei, WuJie, DonShan and LouDon. The estimated arsenic concentrations are highest $(70.32 \mu \mathrm{g} / \mathrm{L})$ in the YiLan and the JhungWei townships. The estimated TR values are ten times higher than an acceptable standard in the arsenic-affected townships. The highest TR values were 145.5 and 91.2 times higher than an acceptable standard for males and females, respectively. The estimated annual mortalities due to arsenic-induced internal cancers that occurred in the YiLan township (ten cases), LouDon (five cases), WuJei (three cases), JhungWei (two cases) and DonShan (one case), and the highest number of mortalities per year in the study area is 24 (five mortalities per 100,000 persons). The estimated annual mortality rate due to arsenic-induced internal cancer is lower than the incidence rate of internal cancer of epidemiological studies by other researchers. Residents of the seven arsenic-affected townships (DonShan, JiaoSi, JhungWei, LouDon, TouChen, WuJie and YiLan) should not use of groundwater as drinking water, and use groundwater only for cleaning and washing purposes. The groundwater in other townships in the Lanyang plain shows no adverse effects on human health.

\section{Acknowledgments}

We would like to thank the Environmental Protection Bureau of the YiLand County Government of the Republic of China and Professor Hann-Chyuan Chiang of National I-Lan University for providing data.

\section{References}

ATSDR. Toxicological profile for arsenic, update. Atlanta: Agency for Toxic Substances and Disease Registry; 1993.

Brown KG, Chen CJ. Significance of exposure assessment to analysis of cancer risk from inorganic arsenic in drinking water in Taiwan. Risk Anal 1995; 15:475-84.

Castrignanò A, Goovaerts P, Lulli L, Bragato GA. Geostatistical approach to estimate probability of occurrence of Tuber melanosporum in relation to some soil properties. Geoderma 2000;98: 95-113.

Chen CJ. Epidemiological study of residents associated with arsenic in drinking water in the Lanyang plain (I). NSC86-2314-B-002-336. ROC: Natl Sci Council; 1997.
Chen CJ, Wang CJ. Ecological correlation between arsenic level in well water and age-adjusted mortality from malignant neoplasma. Cancer Res 1990;50:5470-4.

Chen KP, Wu HY, Wu TC. Epidemiologic studies on blackfoot disease in Taiwan. 3. Physicochemical characteristics of drinking water in endemic blackfoot disease area. Memoirs. Coll Med Natl Taiwan Univ 1962;8:115-29.

Chen CJ, Chuang YC, Lin TM, Wu HY. Malignant neoplasma among residents of a blackfoot disease-endemic area in Taiwan: high arsenic artesian well water and cancers. Cancer Res 1985;45: 5895-9.

Chen CL, Hsu LI, Chiou HY, Hsueh YM, Chen SY, Wu MM, Chen CJ. Ingested arsenic, cigarette smoking, and lung cancer risk. JAMA 2004;292:2984-90.

Chen SL, Yeh SJ, Lin TH. Trace element concentration and arsenic speciation in the well water of a Taiwan area with endemic blackfoot disease. Biol Trace Elem Res 1995;48(3):263-74.

Chiou HY, Huang WI, Su CL. Dose-response relationship between prevalence of cerebrovascular disease and ingested inorganic arsenic. Stroke 1997;28:1717-23.

Chiou HY, Chiou ST, Hsu HH, Wei ML, Hsu YM, Chen CJ. Risk of cancer at all sites combined and ingestion of various elements through well water among residents of the Lanyang Basin, Taiwan. New Taipei J Med 2000;2:57-65.

Chiou HY, Chiou ST, Hsu YH, Chou YL, Tseng CH, Wei ML, et al. Incidence of transitional cell carcinoma and arsenic in drinking water: a follow-up study of 8120 residents in an arseniasis-endemic area in northeastern Taiwan. Am J Epidemiol 2001;153:411-8.

Choi K, Serre ML, Christakos G. Efficient mapping of California mortality fields at different spatial scales. J Expo Anal Environ Epidemiol 2003;13(2):120-33.

Christakos G. Modern spatiotemporal geostatistics. New York: Oxford University Press; 2000. p. 304.

Cressie N. Fitting variogram models by weighted least square. Math Geol 1985;7:563-86.

Crump KS. A new method for determining allowable daily intakes. Fundam Appl Toxicol 1984;4:854-71.

David JK, Montalbano D. The reproductive effects assessment groups report on the mutagenicity of inorganic arsenic. Environ Mutagen 1985;7:787-804.

DOH. Prevention and cure to cancer: liver cancer. Department of Health, Taiwan (ROC). http://www.doh.gov.tw/2002.

Deutsch C, Journel A. GSLIB: geostatistical software library and user's guide. New York: Oxford University Press; 1998.

EPA. Drinking water safety handbook. 2nd ed. Taiwan (ROC): Environmental Protection Administration; 1998.

EPB. Survey of arsenic contents of drinking water (surface water and groundwater) in YiLan County. Environmental Protection Bureau, YiLan County, Taiwan (ROC) Report; 1997.

EPB. Survey of arsenic contents of drinking water (surface water and groundwater) in YiLan County. Environmental Protection Bureau, YiLan County, Taiwan (ROC) Report; 1998.

EPB. Survey of arsenic contents of drinking water (surface water and groundwater) in YiLan County. Environmental Protection Bureau, YiLan County, Taiwan (ROC) Report; 1999.

Gaus I, Kinniburgh DG, Talbot JC, Webster R. Geostatistical analysis of arsenic concentration in groundwater in Bangladesh using disjunctive kriging. Environ Geol 2003;44:939-48.

Goovaerts P. Geostatistics for natural resources evaluation. New York: Oxford University Press; 1997. p. 259-368.

Istok JD, Pautman CA. Probabilistic assessment of groundwater contamination 2. Results of case study. Ground Water 1996;34(6): $1051-64$. 
Jang CS, Liu CW, Lin KH, Huang FM, Wang SW. Spatial analysis of potential carcinogenic risks associated with ingesting arsenic in aquacultural tilapia (Oreochomis mossambicus) in blackfoot disease hyperendemic areas. Environ Sci Technol 2006;40:1707-13.

Journel AG, Huijbregts CJ. Mining geostatistics. San Diego: Academic Press; 1978.

Juang KW, Lee DY. Simple indicator kriging for estimating the probability of incorrectly delineating hazardous areas in a contaminated site. Environ Sci Technol 1998;32:2487-93.

Juang KW, Chen YS, Lee DY. Using sequential indicator simulation to assess the uncertainty of delineating heavy-metal contaminated soils. Environ Pollut 2004;127:229-38.

Lai MS, Hsueh YM, Chen CJ, Shyu MP, Chen SY, Kuo TL, et al. Ingested inorganic arsenic and prevalence of diabetes mellitus. Am J Epidemiol 1994;139:484-92.

Lamm SH, Engel A, Penn CA, Chen R, Feinleib M. Arsenic cancer risk confounder in southwestern Taiwan data set. Environ Health Perspect 2006;114:1077-82.

Lee TC, Tanaka N, Lamb PW, Barrett JC. Induction of gene amplification by arsenic. Science 1988;241:79.

Lee SJ, Serre ML, Christakos G. Bayesian maximum entropy mapping of arsenic using $\mathrm{pH}$-arsenic empirical laws. ESE Research Notes, vol. 2, No. 1. Chapel Hill, USA: Department of Environmental Sciences and Engineering, University of North Carolina; 2005.

Lin YP, Chang TK, Shih CW, Tseng CH. Factorial and indicator kriging methods using a geographic information system to delineate spatial variation and pollution sources of soil heavy metals. Environ Geol 2002;42:900-9.

Liu CW, Jang CS, Liao CM. Evaluation of arsenic contamination potential using indicator kriging in the Yun-Lin aquifer (Taiwan). Sci Total Environ 2004;321:173-88.

Morales KH, Ryan L, Kuo TL, Wu MM, Chen CJ. Risk of internal cancers from arsenic in drinking water. Environ Health Perspect 2000;108:655-61.

National Research Council. Arsenic in drinking water. Washington DC: Natl Acad Press; 1999.

National Research Council. Arsenic in drinking water: 2001 update. Washington DC: Natl Acad Press; 2001

Oyedele DJ, Amusan AA, Obi A. The use of multiple-variable indicator kriging technique for assessment of the suitability of an acid soil for maize. Trop Agric 1996;73(4):259-63.

Preez HH, Heath RGM, Sandham LA, Genthe B. Methodology for the assessment of human health risks associated with the consumption of chemical contaminated freshwater fish in South Africa. Water SA 2003;29:69-90.

Saisana M, Dubois G, Chaloulakuo A, Spyrellis N. Classification criteria and probability risk maps: limitations and perspectives. Environ Sci Technol 2004;38:1275-81.
Serre ML, Kolovos A, Christakos G, Modis K. An application of the holistochastic human exposure methodology to naturally occurring arsenic in Bangladesh drinking water. Risk Anal 2003;23 (3):515-28.

Shen HH. Linking a Life-stage PBPK Model and Epidemiological Data to Enhance Cancer Risk Assessment of Human Exposed to Arsenicals. Master Thesis. Department of Bioenvironmental Systems Engineering, National Taiwan University, Taiwan; 2006.

Shen YS, Chin CS. Relation between blackfoot disease and pollution of drinking water by arsenic in Taiwan. New York: Pergamon Press; 1964.

Smedley PL, Kinniburgh DG. A view of the source, behaviour and distribution of arsenic in natural waters. Appl Geochem 2002;17: 1093-103

Smith JL, Halvorson JJ, Papendick RI. Using multiple-variable indicator kriging for evaluating soil quality. Soil Sci Soc Am J 1993;57:743-9.

Snow ET, Sykora P, Durham TR, Klein CB. Arsenic, mode of action at biologically plausible low dose: what are the implications for low dose cancer risk? Toxicol Appl Pharmacol 2005;207(2S):557-64.

Tseng WP. Effects and dose-response relationships of skin cancer and blackfoot disease with arsenic. Environ Health Perspect 1977;19: 109-19.

USEPA. Special report on ingested inorganic arsenic: skin cancer; nutritional essentiality. EPA/625/3-87/013. Washington DC: US Environmental Protection Agency, Risk Assessment Forum; 1988.

USEPA. Risk-based concentration table. January-June 1996. Region 3, Philadelphia PA: US Environmental Protection Agency; 1996.

van Meirvenne M, Goovaerts P. Evaluating the probability of exceeding a site-specific soil cadmium contamination threshold. Geoderma 2001;102:75-100.

Vieira V, Webster T, Aschengrau A, Ozonoff D. A method for spatial analysis of risk in a population-based case-control study. Int J Hyg Environ Health 2002;205:115-20.

WHO. Environmental health criteria 18: arsenic. Switzerland: World Health Organization; 1981.

Wu MM, Kuo TL, Hwang YH, Chen CJ. Dose-response relation between arsenic well water and mortality from cancers and vascular diseases. Am J Epidemiol 1989;130:1123-32.

Yang CY, Chang CC, Tsai SS, Chuang HY, Ho CH, Wu TN. Arsenic in drinking water and adverse pregnancy outcome in an arseniasisendemic area in northeastern Taiwan. Environ Res 2003;91:29-34.

Yu WH, Harvey CM, Harvey CF. Arsenic in groundwater in Bangladesh: a geostatistical and epidemiological framework for evaluating health effects and potential remedies. Water Resour Res 2003;39(WES 1):1-17. 